KUML 1997-98 


\section{KUML 1997-98 Årbog for Jysk Arkæologisk Selskab}

With summaries in English 
Redaktion: Hans Jorgen Madsen og Jesper Laursen

\section{Omslag: Louise Hilmar}

Tilrettelagning: Narayana Press

Tryk: Narayana Press

Skrift: Bembo 12/13

Papir: $115 \mathrm{~g}$ Arctic Silk

Copyright (C) 1998 by Jysk Arkaologisk Selskab

ISBN 87-7288-597-1

ISSN 0454-6245 


\section{Indhold/Contents}

Hans Jorgen Madsen og Else Roesdahl: Olaf Olsen 70 år $\ldots \ldots \ldots \ldots \ldots \ldots \ldots \ldots$

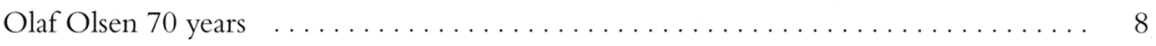

Søren H.Andersen: En mønstret pragtøkse fra ældre Ertebølletid $\ldots \ldots \ldots \ldots \ldots \ldots$.

A Magnificent ornamented axe from the Early

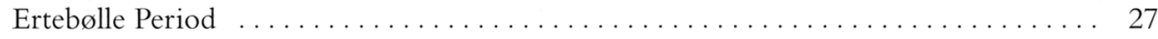

Henrik Skousen: Rønbjerg Strandvolde - en kystboplads

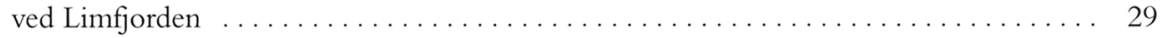

Rønbjerg Strandvolde - a coastal settlement by the Limfjord $\ldots \ldots \ldots \ldots \ldots \ldots \ldots 71$

Lisbeth Christensen: Vandet skole - en ældre romertidsgrav med

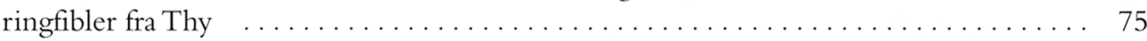

An Early Roman Iron Age grave with ring brooches from

Vandet School in Thy ........................................ 103

Bjarne Henning Nielsen: Jernalderfund fra Egådalen . . . . . . . . . . . . . . . . . 105

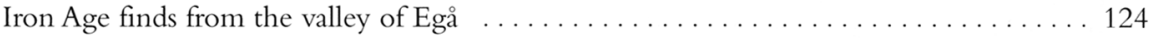

Elisabeth Barfod Carlsen: Et smykke i slægt med guldbrakteaterne $\ldots \ldots \ldots \ldots \ldots \ldots . \ldots 127$

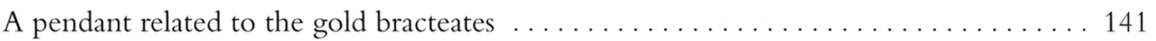

Claus Feveile, Stig Jensen og Kaare Lund Rasmussen: Produktion

af drejet keramik i Ribeområdet i sen yngre germansk jernalder $\ldots \ldots \ldots \ldots \ldots \ldots 143$

The production of thrown pottery in the Ribe area towards

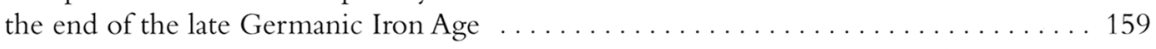

Ole Crumlin-Pedersen: Skibsfundene fra Hedeby $\ldots \ldots \ldots \ldots \ldots \ldots \ldots \ldots$

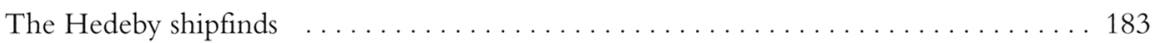

Anne Pedersen: Bidselbeslag fra Bøgeskov Strand . . . . . . . . . . . . . . . . . . . 185

A Harness Cheek-piece from Bøgeskov Strand ....................... 194

Bente Holmberg og Jan Skamby Madsen: Da kom en snekke ... . . . . . . . . . . . . . 197

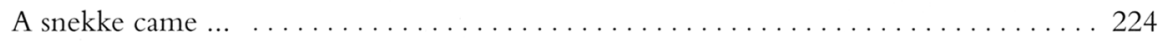

Hans Skov: Udgravningerne i Århus Midtby 1994-97 . . . . . . . . . . . . . . . . 227

The excavations in the centre of Aarhus 1994-97 . . . . . . . . . . . . . . . . . 292

Thomas Bertelsen: Kirketage ........................................ 295

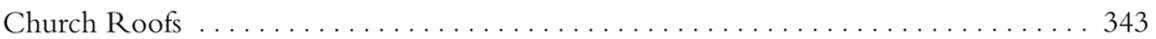

Anmeldelser .................................................. 347

Jysk Arkæologisk Selskab 1997 . . . . . . . . . . . . . . . . . . . . . . . . 369

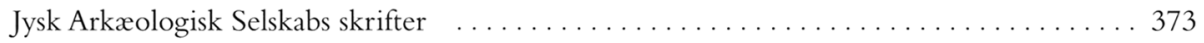




\title{
En mønstret pragtøkse fra ældre Ertebølletid
}

\author{
Af Søren H. ANDERsen
}

Fund af mønstrede hjortetaksøkser fra ældre stenalder hører absolut til sjældenhederne - og især, når det drejer sig om en oldsag af en så fornem kvalitet som den, der skal omtales i det følgende, fig.1.

Hjortetaksøksen er fundet for ca. 50 år siden ved uddybningsarbejde $\mathrm{i}$ forbindelse med kajanlæg ud for Skærbækværket. ${ }^{1} \mathrm{Om}$ fundforholdene kan følgende berettes: Ifølge de tilgængelige oplysninger skulle øksen være opgravet med maskine fra et sted på havbunden, hvor der var et tørvelag indlejret mellem ler (undergrund) og et dækkende sandlag (havbund). Sammen med hjortetaksøksen blev der fundet træstammer, uroksehorn og hjortegevir. Denne beskrivelse viser, at det er et undersøisk kulturlag eller "udsmid" fra en nærliggende kystboplads, der er blevet gennemgravet ved anlægsarbejdet. Dette passer fint med, at Skærbæk netop ligger i den del af landet, der siden ældre stenalder er sænket ca. 0$1 \mathrm{~m}$ i forhold til vore dages havniveau. ${ }^{2}$

Hjortetaksøksen må derfor opfattes som et helt udslidt stykke, som er kasseret på en boplads og siden er endt i affaldslaget. Af det øvrige fundmateriale er der i dag kun bevaret en trykstok på Nationalmuseet. ${ }^{3}$

Der er tale om en hjortetaksøkse af typen med skafthul nær rosenkransen og lidt skæv æg. Den er stærkt opskærpet, men æggen er fortsat meget skarp, selvom den har et lille "skår", der er slidt delvis væk. Råmaterialet er en kastet kronhjortetak, hvis rosenkrans er fjernet; skafthullet er boret imellem første og anden sidespros, hvor den første er skåret helt væk, mens der stadig ses en smule af basis af den anden sidegren. Længden er 17,7 cm, bredden er 4,6 cm og tykkelsen er $4 \mathrm{~cm}$ (begge mål over skafthullet). Skafthullet er konisk, hvorved åbningsdiameteren i den ene side er $2,6 \mathrm{~cm}$ og $3 \mathrm{~cm}$ i den anden side.

Øksen er meget velbevaret, og farven er gulhvid. Overfladen er glat, fuldstændig blank og stærkt skinnende af slid - selv i skafthullet; der er tale om en af de mest blankslidte økser, jeg har set fra danske fund, og selv på takkens basis er der dybe, parallelle slidridser. 


\section{Ornamentik}

Overfladen er dækket af geometrisk ornamentik, hvoraf hovedparten danner et regelmæssigt mønster, der er udført med en fin tynd indridsning i den glatskrabede overflade, fig. 1-2. Der findes dog også partier, der er dækket med en mere uregelmæssig mønstring med en noget kraftigere og dybere indridset streg.

Det dominerende motiv er et netmønster, som gentages i forskellige variationer. Det dækker overfladen fra rosenkransen og indtil ca. $3 \mathrm{~cm}$ forbi skafthullet, men er flere steder slidt bort - især ved rosenkransen og omkring første sidegren. Mønstringen er delvis fjernet ved æggen som følge af opskærpning, men det er åbenbart, at motiverne oprindelig er fortsat og har dækket et endnu større stykke af overfladen.

"Netmotivet" er meget regelmæssigt og består af små, rektangulære eller kvadratiske firkanter, som skiftevis er blanke eller er udfyldt med tætte parallelle streger; mønstret kommer derved til at ligne et skakbræt. Kompositionen er struktureret således, at maskerne følger øksens længderetning, mens de udfyldende tværstreger står vinkelret herpå. Denne regelmæssige, langsgående ornamentik brydes af to mindre felter med masker, der er rhombiske og som i modsætning til resten stråler skråt ud fra skafthullet, og samtidig er "nettet" mere løst i kompositionen.

Endvidere ses ornamentik i form af fint indridsede, 2-3 mm lange streger, der stråler radiært ud fra kanten af skafthullets største åbning; dette motiv dækker hen over netmønstret og er altså yngre end dette. Tangentialt til skafthullet ses også et ca. $1 \mathrm{~cm}$ bredt og $8 \mathrm{~cm}$ langt, smalt bånd udfyldt med rhomber uden udfyldende tværstreger; desuden er der tre korte, smalle bånd med parallelle tværstreger (længden er $2-3 \mathrm{~cm}$ og bredden er $0,5 \mathrm{~cm})$.

På den modsatte side ses ligeledes to parallelle bånd, henholdsvis 3 og 4 $\mathrm{cm}$ lange, som er dannet af tæette, fint indridsede 4-5 $\mathrm{mm}$ lange og parallelle streger. Da alle disse bånd også løber fra skafthullet mod æggen, er de ligeledes med til at understrege den langsgånde rytme i kompositionen. Alle de nævnte ornamenter er udført med samme fine indridsningsteknik.

Fire steder på øksen, som ikke har været dækket af dette skakbrætmønster, er udfyldt med en mere uregelmæssig krydsskravering og et løst "netfelt". Disse motiver er ikke så klart strukturerede og regelmæssige som de førstnævnte, og samtidig er disse mønstre udført med en dybere og grovere indridsningsteknik, fig. 1. Den "grove" mønstring ses især i området mellem rosenkrans og skafthul samt ved æggen.

Da den grovere/dybere krydsskravering flere steder dækker netmønstringen, må den være den yngste.

En mønstring, der er udført med en både fin og noget grovere teknik og således, at den fine er ældst, er et karakteristisk træk ved flere andre 

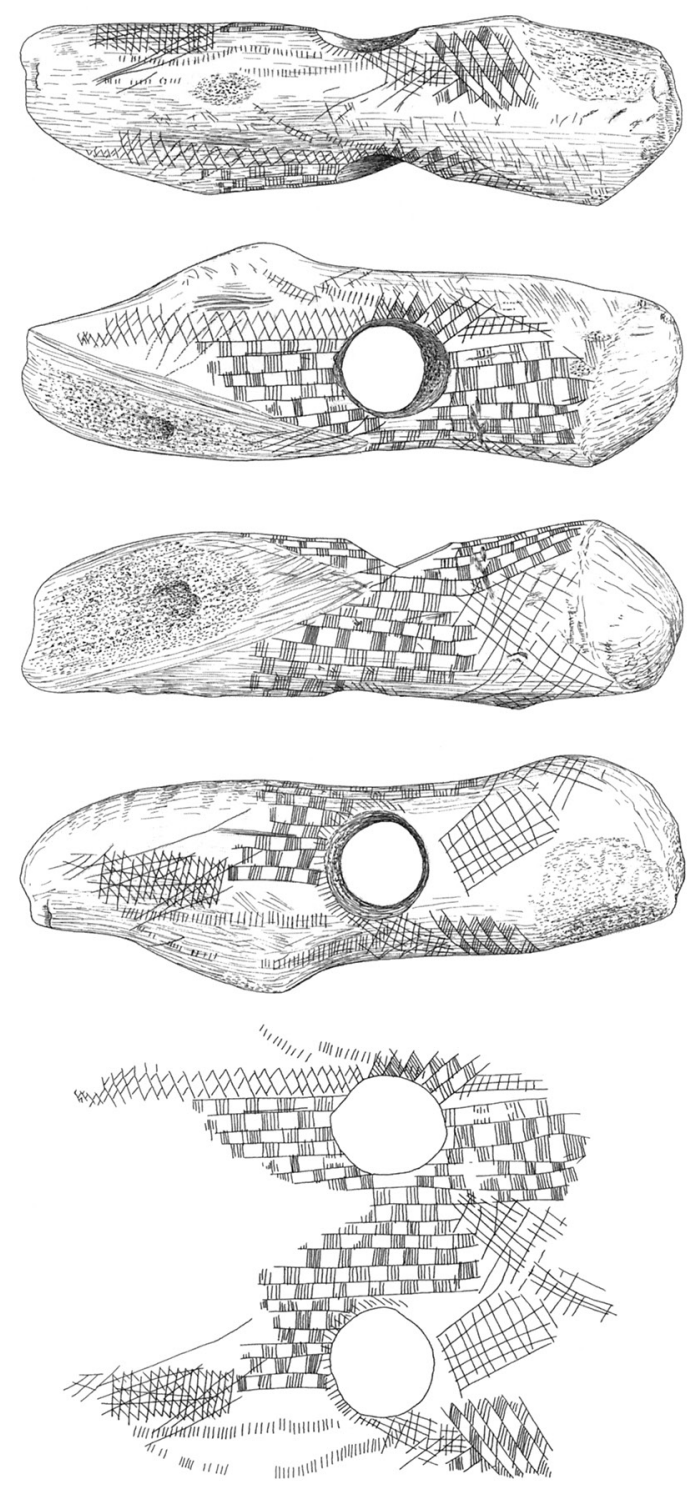

Fig. 1. Udtegning af den samlede ornamentik på hjortetaksøksen fra Skærbæk. Tegning: Eva Koch Nielsen 1:2.

The complete ornamentation of the antler axe from Skærbæk. Drawn by Eva Koch Nielsen 1:2. 


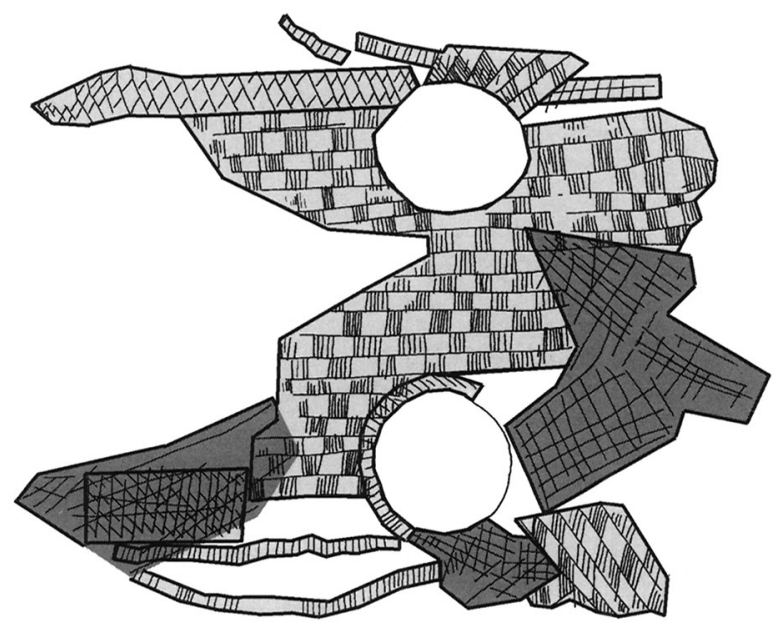

Fig. 2. Udtegning af den samlede ornamentik på hjortetaksøksen fra Skærbæk. Med grå raster er de enkelte mønsterfelter markeret.

The complete ornamentation on the antler axe from Skærbæk. The individual pattern areas are marked in a grey tone.

jyske hjortetaksøkser fra ældre Ertebølletid, f. eks. fra Brabrand, Hevring, Horsens og Kolding Fjord. ${ }^{4}$

En undersøgelse af motiverne og den anvendte teknik viser, at ornamentikken kan inddeles i mindst 15 felter, fig. 2. I flere tilfælde kan aldersforholdet mellem de enkelte felter bestemmes, men der kan ikke opstilles nogen samlet rækkefølge for alle de indridsede områder. Deres antal og fladedækkende omfang tyder dog på, at mønstringen ikke er lavet på en gang, men over længere tid.

\section{Datering}

Hjortetaksøksen kan ikke dateres præcist ud fra fundforholdene, men den tidligere omtalte trykstok giver dog et vist fingerpeg, da dens længde (ca. $21 \mathrm{~cm}$ ) viser, at den tilhører ældre Ertebøllekultur, ca. 5400 f. Kr.. Under forudsætning af at oldsagerne er samtidige, giver trykstokken altså en grov datering af hele fundet til ældre Ertebøllekultur.

Hjortetaksøksens form, ornamentik og den anvendte indridsningsteknik kan også give et fingerpeg om dens datering.

Hjortetaksøkser med skafthul ved rosenkransen og lidt skæv æg forekommer i tidsrummet fra Kongemosekulturen og videre frem til ældre og mellemste Ertebøllekultur. 
Skakbrætmotivet er en variant af netmønstret, der er et af de almindeligste og mest karakteristiske motiver for ældre Ertebøllekultur, hvor det både kendes fra hjortetaksøkser, hjortetaksskafter, flåknive og ravsmykker. ${ }^{5}$ Det samme gælder de langsløbende bånd af små, korte tværstreger. Netmotivet kendes i mange forskellige udformninger, men oftest er maskerne rhombiske eller trekantede. Det er usædvanligt, at maskerne er firkantede som på Skærbækøksen, men findes - som små felter - både på en hjortetaksøkse og et skaft fra bopladsen Bergmansdal nær Helsingør (ældre Ertebøllekultur) og på en hjortetaksøkse fra en Ertebøllegrav ved Fannerup (Djursland), fig. $4 .^{6}$

Også Skærbækøksens motiv med radiære streger, som stråler ud fra skafthullet kendes blandt andet fra to andre, jyske hjortetaksøkser fra henholdsvis Horsens Fjord og Lerkenfeldt Å (også æeldre Ertebølletid). ${ }^{7}$

Endelig skal også nævnes, at teknikken med at indridse mønstrene med fine tynde streger netop er karakteristisk for udsmykningen af redskaber fra ældre Ertebøllekultur.

Alle disse forskellige elementer peger på, at hjortetaksøksen fra Skærbæk skal dateres til ældre Ertebøllekultur, det vil sige ca. 5400 - 4700 f. Kr..

\section{Andre fund}

Mønstrede hjortetaksøkser fra ældre Ertebølletid er forholdsvis almindelige i Jylland, hvor de især kendes fra centrale Østjylland, fig. 7. Flere forhold gør hjortetaksøksen fra Skærbæk usædvanlig i forhold til det øvrige danske materiale. Først og fremmest er den store regelmæssighed et træk, som ikke - eller kun i mindre grad - genfindes på andre hjortetaksøkser; hertil kommer mønstringens fladedækkende karakter, hvilket heller ikke er almindeligt, og endelig må det usædvanligt voldsomme slid anføres.

Hjortetaksøksen fra Skærbæk må henføres til en lille, "eksklusiv" gruppe af danske, mønstrede hjortetaksøkser, der er karakteriseret ved både at være kraftigt blankslidte, at have mange successive, overlappende eller "konfuse" mønstre, som dækker en stor del af overfladen, og som er udført i mange omgange med forskellige teknikker og komposition, $f$. eks. økserne fra Bogø Nor på Langeland, Torpegård på Vestfyn og Værebro Å på Sjælland, fig. 3. ${ }^{8}$ Der er ikke tvivl om, at øksen fra Skærbæk oprindelig har været af samme størrelse og type som de tre ovennævnte $ø$ kser, selvom den er opskærpet og derfor er meget kortere idag.

På denne gruppe hjortetaksøkser er den fladedækkende udsmykning ikke lavet på én gang, men er tværtimod en funktion af gentagne mønstringer, der til slut har dækket hele overfladen. Det fremgår med stor tydelighed af analyser af økserne fra Torpegård og Bogø Nor - og altså også 

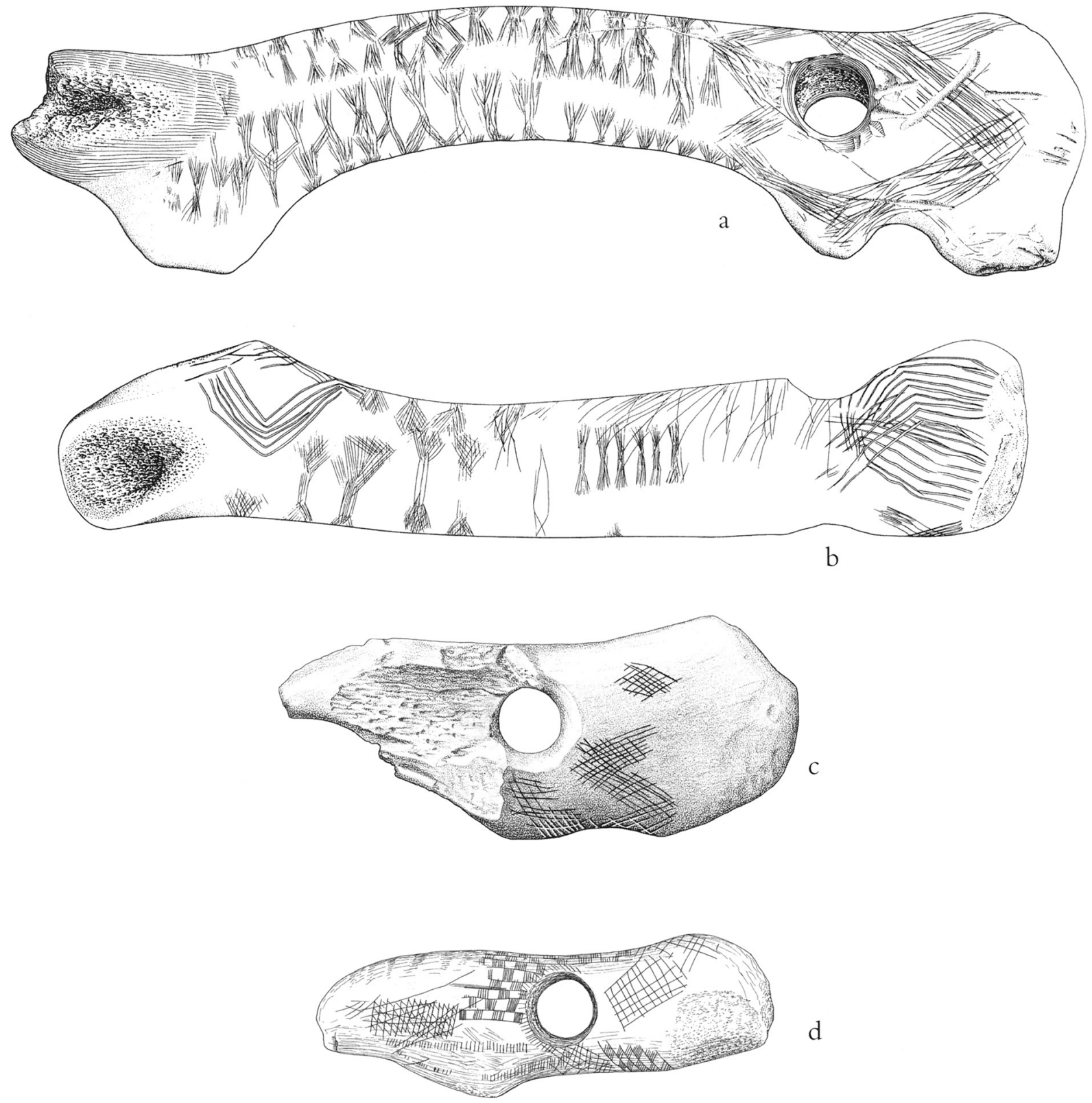

Fig. 3. Sammenstilling af de mønstrede hjortetaksøkser fra Bogø Nor (a), Torpegård (b), Fannerup (c) og Skærbæk (d). Torpegårdøksen er af samme type som de andre, men er af hensyn til ornamentikken vist fra den modsatte side. Tegning:J. Kirkeby; her efter Kuml 1981. Alle økser er i 1:2.

Juxtaposition of the ornamented antler axes from Bogø Nor, Torpegård, Fannerup and Skærbæk. The Torpegard axe is a similar type to the others but, because of the ornamentation, it has been shown from the opposite side. Drawing by J. Kirkeby (from Kuml 1981). Scale 1:2. 
af øksen fra Skærbæk. ${ }^{9}$ En lang brugstid harmonerer også med det voldsomme slid af overfladen og Skærbækøksens kraftige opskærpning.

$\mathrm{Ud}$ fra de ovennævnte træk adskiller disse hjortetaksøkser sig først og fremmest fra de uornamenterede, men også fra de økser, som kun er lidt udsmykkede. De kraftigt ornamenterede hjortetaksøkser må regnes for særlige "magiske" eller rituelle stykker. Deres skader og opskærpning viser dog, at de ikke udelukkende har været rituelle, men også har tjent dagligdags gøremål, hvorved de er blevet slidt. Disse økser har på en måde fungeret som en skoletavle eller vægavis, hvorpå der over længere tid jæevnligt skrives eller ridses noget nyt. I tidens løb slides noget af dette væk, andet overtegnes, og endelig udfyldes tomme felter, hvorved øksen til slut fremstår med en fuldstændig mønsterdækket overflade. Til trods for den overmåde store tidsforskel er en nærliggende analogi til de danske hjortetaksøkser udsmykningen i de senpalæolitiske huler i Sydvesteuropa, hvor der netop også både er påført nye billeder og motiver og samtidig er ældre udsmykning(-er) jævnligt overmalede. Både hjortetaksøkser og klippehuler afspejler højst sandsynligt en beslægtet rituel baggrund og anvendelse af udsmykningen.

Der er ingen tvivl om, at disse økser må have været i brug i meget lang tid. Det viser både successionen i mønstringen, det voldsomme slid af overfladen og endelig også opskærpningen. Man kan så stille sig det spørgsmål, hvorfor en sådan økse sluttelig ender i et udsmidslag ?

Skærbæk øksen adskiller sig lidt fra de øvrige danske, mønstrede hjortetaksøkser ved, at det ældste, fladedækkende netmotiv fra starten af tilsyneladende er blevet indridset på én gang og efter en fast, velkomponeret ide. Set i en større sammenhæng er øksen af en meget sjælden type ikke kun i Jylland, men også i resten af landet. Enkelte, tilsvarende stykker kendes fra Sjælland, f. eks. fra Værebro Å og Åmosen ${ }^{10}$; i Nordtyskland er typen ukendt. ${ }^{11}$

Siden de vestdanske fund af mønstrede hjortetaksredskaber fra Ertebøllekulturen blev behandlet i $1981^{13}$, er der fremkommet flere nye fund.Vigtigst af disse er den mønstrede hjortetaksøkse, fig. 4, fra en Ertebøllegrav ved Fannerup. ${ }^{14}$ Den er af typen med skafthul ved rosenkransen og er kraftigt opskærpet; overfladen er helt glatskrabet og blankslidt, og nakkepartiet er rundt, butslidt - fuldstændig som beskrevet ved øksen fra Skærbæk. Overfladen er helt dækket med geometriske mønstre indridset med en fin, tynd streg. Der kan udskilles tre forskellige motiver, henholdsvis et skakbrætmønster dannet af felter af tæetstillede, parallelle streger skiftende med "åbne", blanke felter; krydsskraverede, zig-zag bånd, der findes lige bag skafthullet - et motiv og en komposition, som genfindes i samme udformning på øksen fra Bogø Nor, ${ }^{15}$ og endelig ses 3-4 bånd, som er indridset på tværs af længderetningen. 

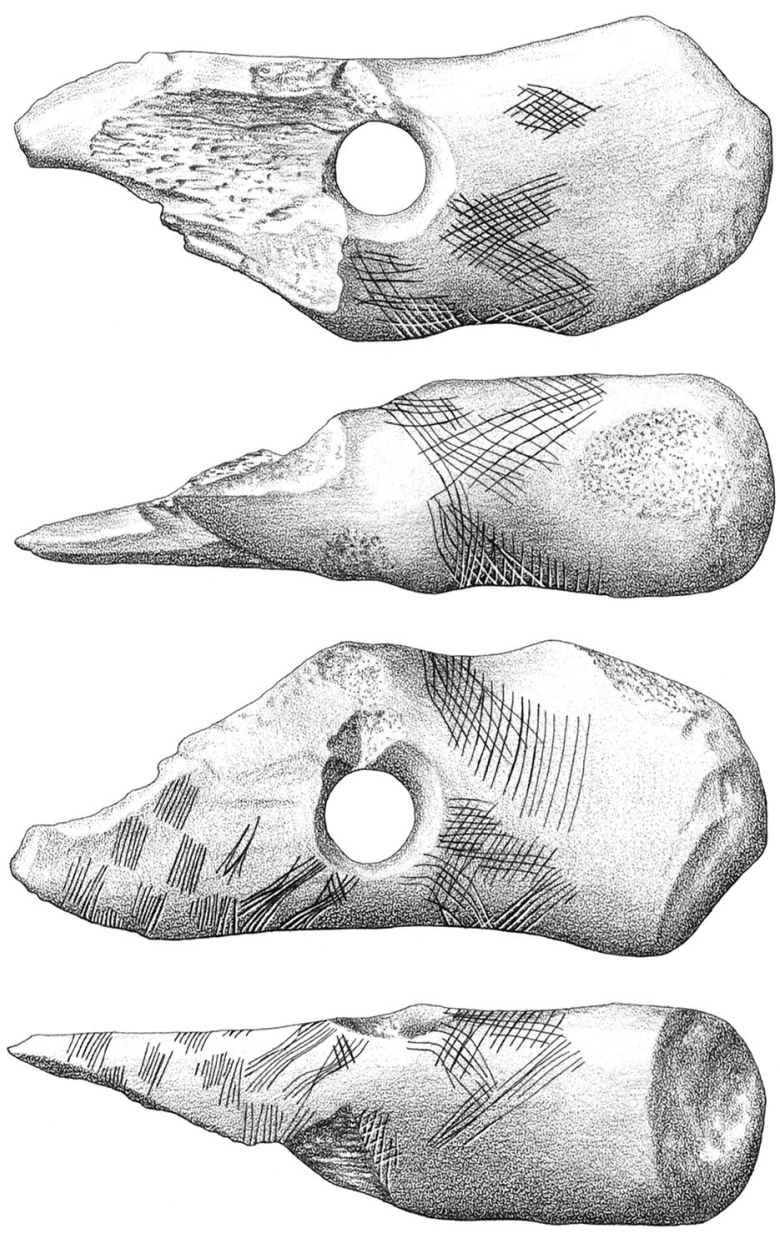

Fig. 4. Mønstret hjortetaksøkse fra Ertebøllegrav ved Fannerup. Tegning: Louise Hilmar. 1:2.

Ornamented antler axe from an Ertebølle grave at Fannerup. Drawn by Louise Hilmar. Scale 1:2.

Denne økse er meget beslægtet med den mønstrede hjortetaksøkse fra Skærbæk (samt stykkerne fra Bogø Nor og Torpegård).

Gravformen daterer øksen til ældre Ertebøllekultur, hvilket svarer til dateringen af Skærbækøksen og de tidligere publicerede, mønstrede økser. ${ }^{16}$

De mønstrede hjortetaksøksers særlige rituelle status understreges af, at de også optræder i (mands-)grave - altså i en helt anden sammenhæng end de enkeltfundne eller fund fra bopladserne.

Hjortetaksøkser og -redskaber forekommer sjældent som gravgods i Ertebøllegrave (Bøgebakken grav 6, Nederst grav 2, Strøby Egede og 

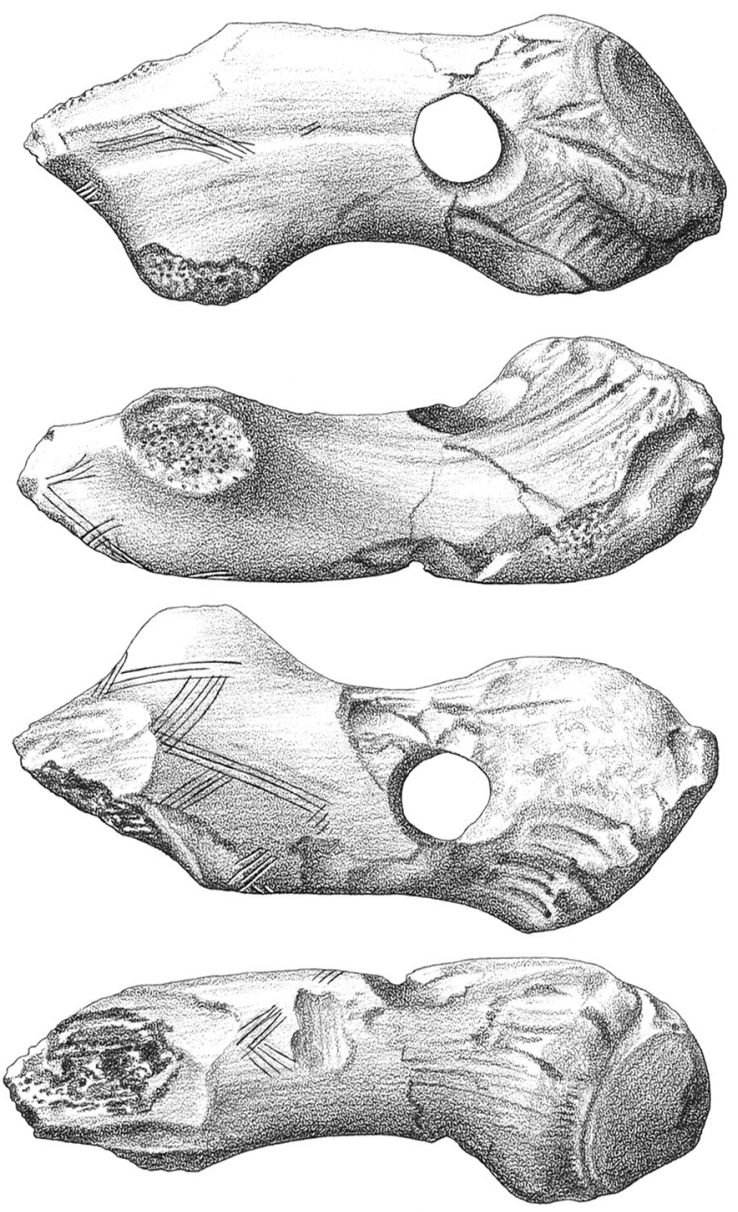

Fig. 5. Mønstret hjortetaksøkse fra køkkenmøddingen "Nederst" i Kolindsund. Tegning Louise Hilmar. 1:2.

Ornamented antler axe from the kitchen midden "Nederst" in Kolindsund. Drawn by Louise Hilmar. Scale 1:2.

Skateholm 1 grav 22). Af disse er økserne fra Fannerup, Strøby Egede og Skateholm mønstrede og viser, at de udsmykkede hjortetaksøkser har været tillagt en særlig symbolsk betydning. Dette synspunkt støttes meget tydeligt af den kendsgerning, at den sidste opskærpning af Fannerupøksen kun er meget overfladisk og nødtørftigt udført; her er det helt tydelig, at det i mindre grad er funktionen som økse end som rituelt objekt i gravsammenhængen, der har spillet den afgørende rolle.

Endvidere kan nævnes, at der i en (hunde)grav fra Skateholm II er fundet et mønstret hjortetaksredskab. ${ }^{17}$

Fra de seneste års udgravninger af køkkenmødingen "Nederst" i Ko- 


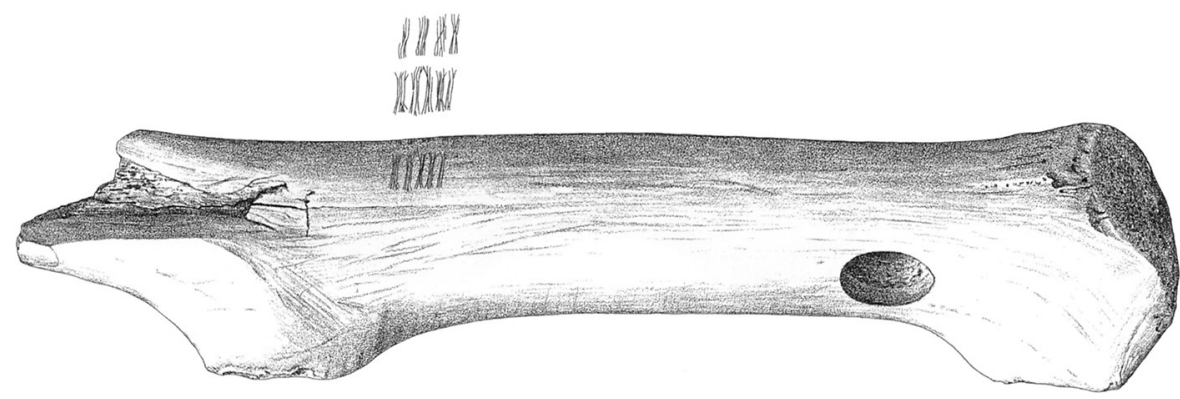

Fig. 6. Mønstret hjortetaksøkse fra Skellerup Enge, Mols. Øksen er af samme form som stykkerne fra Bogø Nor og Torpegård, men kun med ganske lidt ornamentik. Den repræsenterer derfor et tidligt stadium i den udsmykningssekvens, der kan aflæses af de øvrige. Tegning J. MürmannLund. 1:2.

Ornamented antler axe from Skellerup Enge on Mols, East Jutland. The axe has the same form as the pieces from Bogø Nor and Torpegård, but has only a little ornamentation. It there-fore represents an early stage in the ornamentation sequence, which may be seen on the others. Drawing by J. Mürmann-Lund. 1:1.

lindsund ${ }^{18}$ er der også fremkommet en opskærpet hjortetaksøkse af ældre Ertebølletype, fig. 5. Hjortetaksøksens overflade er glatskrabet fra skafthullet og frem mod ægpartiet, der er skadet. På den polerede overflade ses ornamentik i form af fint indridsede, store rhomber, der er udført som bånd af parallelle, fint indridsede streger, fig. 5 - et velkendt Ertebøllemotiv, som også kendes fra hjortetaksøkser fra Brabrand og Dyrholmen. ${ }^{19}$ Øksen, der er et bopladsfund, kan kun dateres groft til ældre Ertebøllekultur.

Fra en usystematisk udgravning i marine, oldsagsrige fundlag ved Skellerup (Sydmols) ${ }^{20}$, stammer den store og meget velbevarede hjortetaksøkse, fig. 6. Bortset fra en afsprængt splint ved æggen er øksen hel; overfladen er glatskrabet og nær æggen er der indridset en gruppe på 5 "kornneg", der står vinkelret på øksens længderetning - fuldstændig som på alle andre beskrevne hjortetaksøkser med dette motiv.

$\varnothing \mathrm{ksen}$ er et enkeltfund og kan derfor kun dateres ud fra sin form, der henfører den til samme type som økserne fra Bogø Nor og Torpegård, d.v.s. ældre Ertebølletid. I umiddelbar nærhed af øksens fundsted har Forhistorisk Museum, Moesgård udført en prøveudgravning i marine lag med oldsager fra ældre Ertebøllekultur. ${ }^{21}$ Fra denne lagserie foreligger en C-14 datering, der gav resultatet $5050 \mathrm{f}$. Kr. (Kal) (K-3097). Uden at der kan gives bevis for, at hjortetaksøksen stammer fra dette fundlag, er det dog meget sandsynligt. Øksens form og udsmykning er i fin overensstemmelse med C-14 dateringen.

Endelig er der for nylig publiceret en sydvestsjællandsk hjortetaksøkse, som er udsmykket med mindst tre felter med "kornneg" kombineret 
Fig. 7. Forekomsten af mønstrede Ertebølleredskaber i Vestdanmark. Den tydelige koncentration af fund i Østjylland er et af de træk, som er med til at understrege denne regions særpræg allerede i ældre Ertebøllekultur; Skærbæk er angivet med "a", Skallerup med "b", Fannerup med "c" og Nederst med "d".

The occurrence of ornamented Ertebølle tools in Western Denmark. The clear concentration of East Jutland finds is one of the features which adds to the understanding of the distinctive character of this region, even in the early Ertebølle Period. Skærbæk is marked by an a.

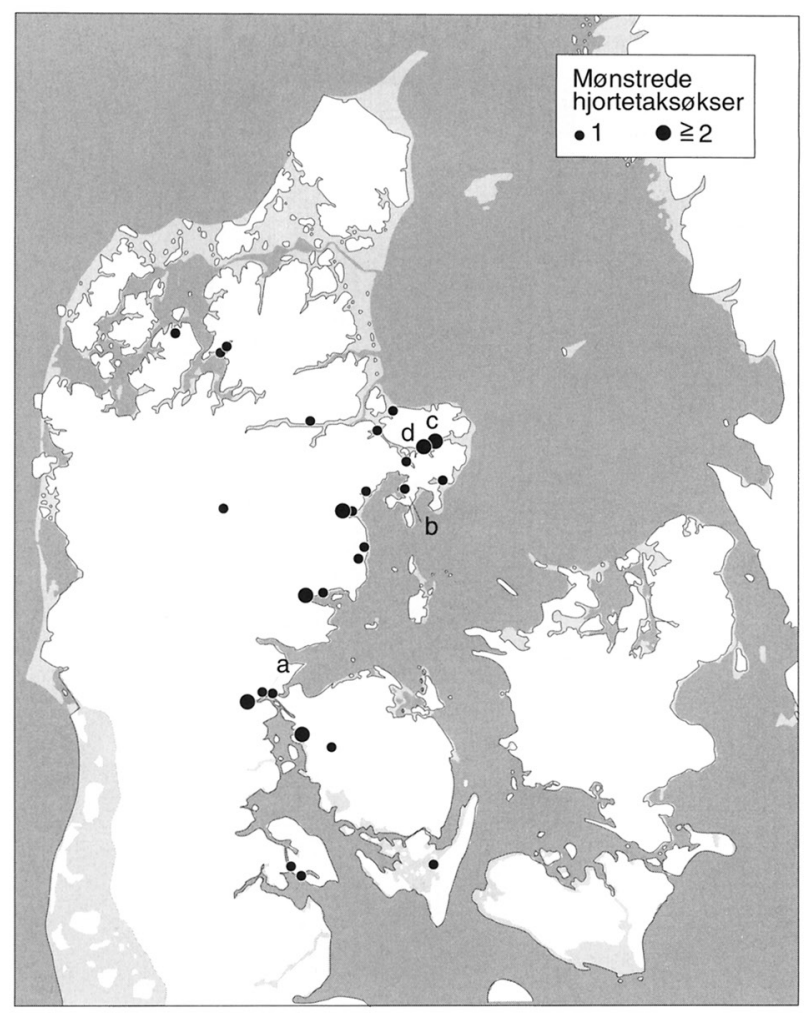

med diffuse stregbundter. Selvom ornamentikken er knapt så stilsikkert udført som de jysk-fynske paralleller, er ligheden med disse dog åbenbar. Den sjællandske hjortetaksøkse stammer fra det submarine Ertebøllefund Korsør Nor, som dateres til overgangen Kongemose-ældre Ertebøllekultur, blandt andet ud fra to $\mathrm{C}-14$ dateringer. ${ }^{22}$

Dette fund er interessant ud fra en geografisk synsvinkel, da denne $ø$ kse indtil videre er det eneste eksempel på "kornnegmotivet" fra området øst for Storebælt; hidtil har motivet kun været kendt fra Vestdanmark, d.v.s. egnene vest for Storebælt og med et særligt tyngdepunkt i Østjylland, fig. 8. Endvidere har motivet været med til at pege på en mulig regional forskel mellem Ertebøllekulturen øst og vest for Storebælt. ${ }^{23}$ Dette fund åbner for to forklaringer: Enten forekommer dette motiv også i ældre Ertebøllekultur i Østdanmark, eller også er der tale om "et lån”, et eksempel på kontakt mellem befolkningsgrupperne henholdsvis øst for og vest for Storebælt i ældre Ertebølletid.

Langt hovedparten af de vestdanske fund af mønstrede hjortetaksøkser fra ældre Ertebølletid er østjyske, fig. 7,- et billede der yderligere bliver markant, hvis man også inkluderer andre fundtyper med ornamentik fra denne tid. Denne fundfordeling skyldes selvfølgelig både bevaringsfor- 


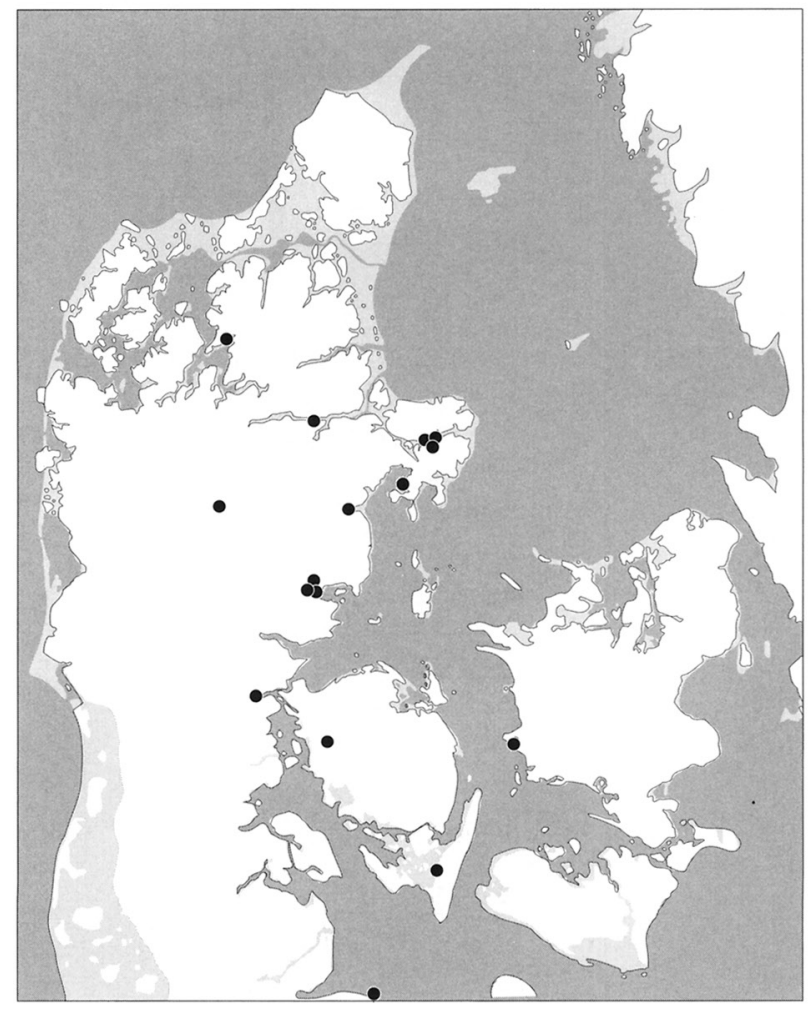

Fig. 8. Udbredelsen af hjortetaksredskaber fra ældre Ertebøllekultur, der er mønstrede med det såkaldte "kornnegmotiv". Selvom grundtrækkene fortsat er de samme, er der idag en endnu tydeligere koncentration omkring Djursland/Mols end tidligere; hertil kommer det nye fund fra Korsør Nor.

The distribution of antler tools from the Early Ertebølle culture ornamented in the sheaf motif. Although the main distribution is still the same, today a more distinct concentration in the Djursland/Mols area is visible. Add to this the new find from Korsør Nor.

hold og udgravningsaktivitet, men det er slående, at der stort set ikke kendes ornamenterede hjortetaksøkser (eller redskaber) i Nordjylland - en egn, hvor der - trods alt - både er mange bopladser, fine bevaringsforhold for organiske levn, og hvor der har været udfoldet en stor arkæologisk udgravningsaktivitet. Der er idag næppe tvivl om, at den geografiske fordeling af de mønstrede genstande fra ældre Ertebøllekultur i Jylland - i hvert fald i nogen grad - afspejler et reelt forhold, et regionalt mønster.

Skærbækøksen hører til de sydligste fund af mønstrede Ertebølleredskaber i Østjylland; at fundene bliver færre sydpå har først og fremmest geologiske årsager, da Ertebøllekystbopladserne syd for Horsens Fjord idag er submarine og kun erkendes ved undersøiske rekognosceringer/udgravninger eller rene tilfældigheder. I kort afstand fra Skærbæk er der fund af mønstrede hjortetaksøkser fra Ertebøllefundene i både Gudsø Vig og Kolding Fjord, fig.7. ${ }^{12}$ 


\section{Sammenfatning}

De nye fund underbygger det billede, der allerede blev fremlagt i 1981 ved den første fremlægning af de vestdanske fund af mønstrede genstande fra Ertebøllekulturen. ${ }^{24}$ Ornamenterede Ertebølleredskaber findes jæunligt, men har en klar kronologisk og geografisk afgræensning. Alle de veldaterede stykker tilhører ældre Ertebøllekultur og har deres hovedudbredelse i Østjylland, hvilket antyder et regionalt præg ved denne egn. Det er især hjortetaksøkser, som er udsmykkede. Efter at gevirets overflade er skrabet glat, er de blevet ornamenteret med indridsede geometriske mønstre, hvor især netmotiver (ofte som rhomber) i flere forskellige variationer er særlig karakteristisk. Et andet karakteristisk mønster er "kornnegmotivet", der kendes fra flere nye østjyske fund, men som nu også er repræsenteret på Sydvestsjælland, hvilket i nogen grad er med til at sløre dette motivs - tidligere påviste - regionale udbredelse. Som noget nyt ses nu også det regelmæssige skakbrætmotiv i Østjylland.

Den helt dominerende teknik er indridsede, fine og tynde streger, der i flere tilfælde dækkes af en yngre, mere grov og dybere teknik.

En mindre, "eksklusiv" gruppe hjortetaksøkser er dækket med mønstre over hele overfladen, og analyser viser, at ornamentikken er påført $i$ mange omgange og over et længere tidsrum. Det stemmer med, at disse $ø$ kser altid er meget blankslidte og i flere tilfælde stærkt opskærpede. Øjensynlig er der her tale om en særlig gruppe "rituelle" økser. Dette synspunkt understreges også af, at en økse med fladedækkende udsmykning nu også er fundet i en grav ved Fannerup.

Det forøgede materiale medfører endvidere, at de stykker og motiver, der tidligere var unika, nu gradvis begynder at finde paralleller og derved danner mindre grupper, f. eks. kan der vises store lighedspunkter mellem hjortetaksøkserne fra Fannerup på Djursland og Bogø Nor på Langeland.

\section{En nydatering af flintæg- dolken fra Flynderhage}

I denne sammenhæng skal opmærksomheden henledes på den velkendte flintægdolk fra Flynderhage køkkenmøddingen i Norsminde Fjord, fig. 9. ${ }^{25}$ Fundoplysningerne kunne ikke bidrage til en nærmere datering, da det blot var registreret, at dolken lå "dybt" i den store køkkenmødding. Ud fra fundsituationen på Flynderhage var der umiddelbart mest grund til at datere dolken til at være samtidig med bopladsens fund fra ældre Ertebøllekultur, men da der på det tidspunkt ikke kendtes andre jyske fund med mønstrede flintægdolke, og alle de østdanske dateredes til Kon- 


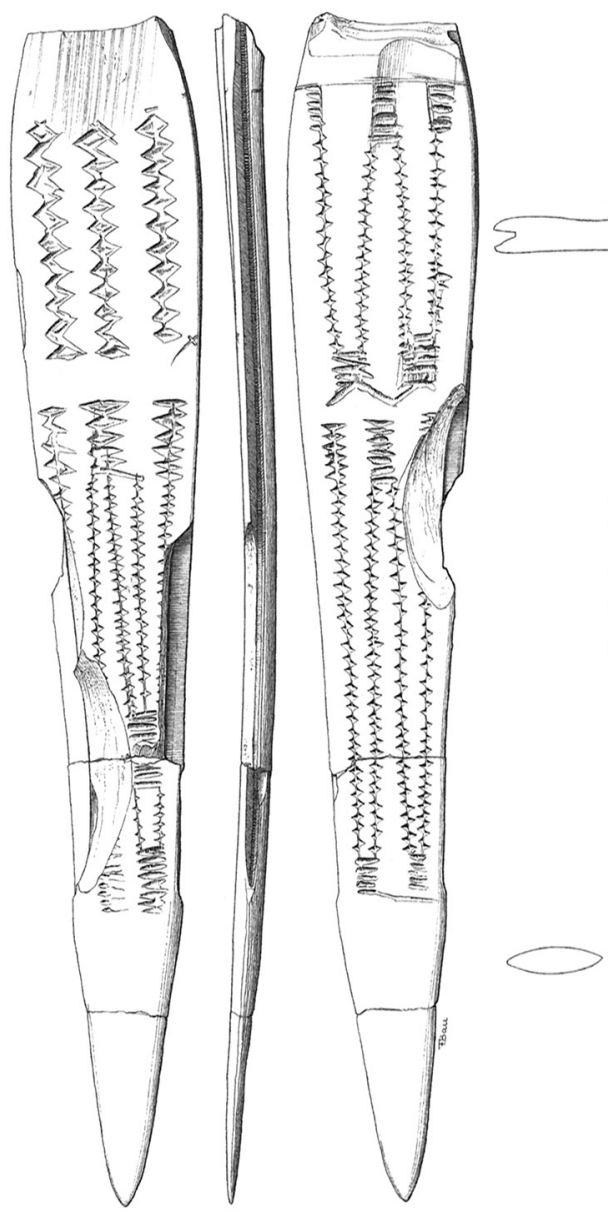

Fig. 9. Mønstret flintægdolk af elsdyrknogle fra Flynderhage. Tegning: F. Bau. 2:3.

Ornamented flint-edge dagger of moose bone from Flynderhage. Drawn by F. Bau. 2:3.

gemosekultur, blev den på grund af sin lighed med de mønstrede dolke fra Sjælland dateret til yngre Kongemosekultur. ${ }^{26}$

I modsætning til de østdanske dolke, der langt overvejende er lange og med parallelle sidekanter, har Flynderhagedolken et mere kort, trekantet omrids. Formmæssigt er der altså forskel mellem Flynderhagedolken og de øvrige danske stykker.

I lyset af nye fund og oplysninger er der imidlertid nu grund til at tage denne datering op til revision.

De seneste års omhyggelige undersøgelser af strandforskydningen $\mathrm{i}$ Atlantisk tid viser, at der er en vertikal højdeforskel på ca. 4-6 m mellem strandbundne bopladser fra Kongemosekultur og ældre/mellemste Ertebøllekultur. ${ }^{27}$ Overføres dette på forholdene i Norsminde fjord, vil det sige, at Kongemosebopladserne i dette område skal findes på dybt vand på kote ca. -3-4 m (hvilket da også svarer til erfaringerne i området, hvor 
Fig. 10. Benspids fremstillet af mønstret flintægdolk af samme art som Flynderhagedolken. På grund af råmaterialet (knogle) er der grund til at tro, at fremstillingen af benspidsen er sket kort tid efter at dolken er blevet kasseret (genbrug). Fra Sølager køkkenmøddingen i Nordsjælland. Tegning: H. Ørsnes. 2:3.

Bone point made from an ornamented flintedge knife of the same type as the Flynderhage knife. Because of the type of raw material (bone), the bone point was most likely made shortly after the knife being discarded (secondary use). From the Sølager kitchen midden in Northern Zealand. Drawn by $\mathrm{H}$. Ørsnes. 2:3.

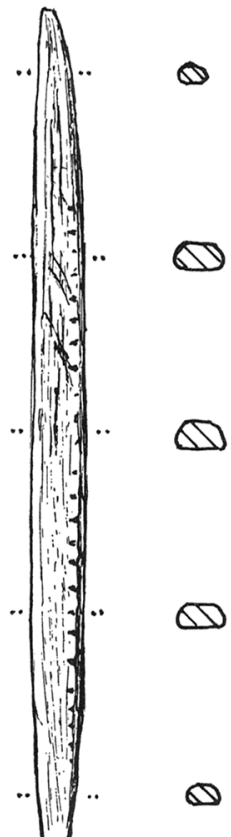

der trods omfattende udgravninger og rekognosceringer i de sidste ca. 40 år stadig ikke er fundet sikre Kongemosebopladser). Da Flynderhagedolken er fundet ca. 2-4 m over havets overflade, er dens fundniveau altså ud fra denne synsvinkel alt for højt til at kunne stamme fra en Kongemoseboplads på dette sted. ${ }^{28}$

Et yderligere aspekt er publikationen af en $13 \mathrm{~cm}$ lang benod af spidsovalt omrids og med trapezoidt tværsnit, som er fundet i lag II i Sølagerkøkkenmøddingen, fig. $10 .{ }^{29}$ Langs benspidsens kanter ses spor af langsgående furer, og på siderne kan der skimtes ornamentik, der er meget beslægtet med motiverne på Flynderhagedolken (sammenlign fig. 9 og 10), og det er nærliggende at slutte, at benspidsen fra Sølager er fremstillet af en flintæogdolk med samme udsmykning som Flynderhagedolken. ${ }^{30}$

Lag II i Sølagerdyngen er C-14 dateret til tidligneolitisk tid (tragtbægerkultur), 3490-3370 f. Kr.(Kal.) (K-1724) - en datering, der er i overensstemmelse med den arkæologisk-typologiske datering af laget. Da der ikke kendes andre eksempler på ornamenterede flintægdolke fra tidligneolitiske fund, er der grund til at antage, at dette stykke er en sekundær indblanding fra et ældre kulturlag på stedet. Kulturlagene ved Sølager ligger på et stejlt skrånende terrain, hvor de gentagne stenalderbebyggelser formodentlig må have ligget oppe på bakkens flade plateau, ved hvis fod de udgravede affaldslag successivt er blevet aflejrede. Det kan derfor an- 


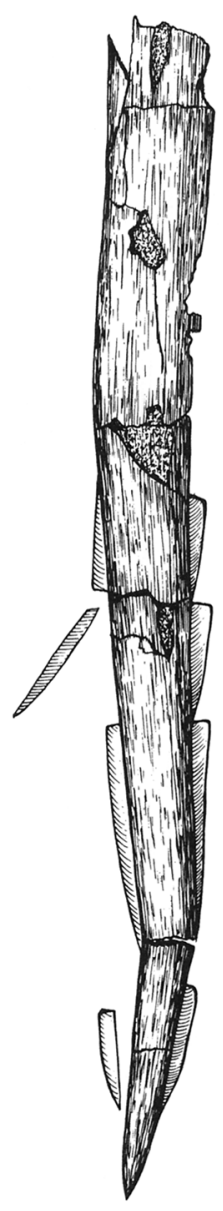

Fig. 11. Flintægdolk fra grav 4 på Bøgebakken, Østsjælland. Tegning: E. Brinch Petersen. 2:3.

Flint-edge dagger from grave 4 at Bøgebakken, Eastern Zealand. Drawn by E. Brinch Petersen. 2:3.

tages, at dolken (og andre oldsager) kan være rutchet ned ad skråningen fra et højere og ældre bebyggelsesniveau og på den måde være endt i lavereliggende, yngre aflejringer. De ældste bebyggelsesspor ved Sølager stammer fra kulturlag tilhørende mellemste Ertebøllekultur, hvilket også underbygges af såvel en typologisk vurdering af de fundne oldsager, som af en C14 datering på 4350 f. Kr. (Kal.) (K-1723).

Endvidere må det erindres, at der fremkom et brudstykke af et flintægspyd i kulturlag 3 på Nors-

lundbopladsen i Norsminde fjord. ${ }^{31}$ For de tre ovennævnte fundsteder gælder, at der ikke i noget tilfælde er konstateret sikre spor af Kongemosekultur, men derimod af kulturlag fra ældre og/eller mellemste Ertebøllekultur. Med hensyn til en datering af de nævnte flintægdolke og flintægspyd gælder, at disse ikke kan være yngre end de lag, hvori de er fremdraget, men derimod godt kan være ældre. For både Flynderhagedolken og flintægspyddet fra Norslund lag 3 gælder, at det trods alle stratigrafiske forbehold er mest sandsynligt, at disse oldsager er samtidige med de lag, hvori de er fremkommet, d.v.s. lag fra ældre/ældste Ertebøllekultur.

Disse iagttagelser peger på, at Flynderhagedolken skal omdateres til ældre/ældste Ertebøllekultur, og denne type bør derfor også indregnes i denne fases redskabsinventar. De sparsomme fund viser, at der ikke er tale om nogen almindelig type, men at oldsagsformen dog forekommer jævnt spredt over hele landet. 
Ovennævnte nydatering af Flynderhagedolken støttes endvidere af fundet af en uornamenteret flintægdolk i grav 4 på gravpladsen Bøgebakken, fig. 11. ${ }^{32}$ Denne grav kan dateres til tidsrummet 5400-4600 f. Kr. (Kal.) (d.v.s. ældre Ertebøllekultur eller Trylleskovfasen på Sjælland). Også i dette tilfælde står vi altså overfor en situation, hvor der forekommer en flintægdolk i en ældre Ertebølle sammenhæng.

Set under en samlet synsvinkel synes alle disse fund at pege på, at flintægdolk og flintægspyd er en del af den ældre Ertebøllekulturs redskabsinventar, og at Flynderhagedolken bør henføres til ældre Ertebøllekultur.

\section{Noter}

1) Hjortetaksøkse fra Skærbækværket. Fundstedet er registreret i Nationalmuseets sognebeskrivelse under nr. 75 af Taulov s., Elbo h., Vejle amt. NM 1 j.nr. 87/50 og j. nr. 6717/88. NM OMA A. 52273. Min gode ven og kollega Flemming Rieck, NMU takkes for tilladelse til at publicere dette enestående stykke.

2) Mertz 1924 .

3) Slagstokken har nummer A. 4444 på Nationalmuseet (OMA).

4) S. H. Andersen 1981, s. 25 og fig. 12.

5) S. H. Andersen 1981 og 1991.

6) Petersen \& Petersen 1979, fig. 6-8 og 10; Rasmussen 1990.

7) S. H. Andersen 1981, s. 10-11 og fig. 2.

8) S. H. Andersen 1981, s. 14-18 og fig. 6-7; Petersen 1971, s. 188-189.

9) S. H. Andersen 1981, s. 13-18.

10) Petersen 1971; Fischer 1985.

11) Iflg. meddelelse fra S. Hartz, Archäeologisches Landesamt, Slesvig.

12) S. H. Andersen 1981

13) S. H. Andersen 1981

14) Rasmussen 1990, s. 31-41. Hjortetaksøksen er gengivet i anf. art. fig. 5-6.

15) S. H. Andersen 1981, s. 16, fig. 7.

16) S. H. Andersen 1981, s. 45-49.

17) Larsson 1988, s. 149.

18) Mathiassen et. al. 1942, s. 59-60; Kannegaard 1990. Upubliceret udgravning. Undersøgelsen er registreret i Djurslands Museum j. nr. 2123, og hjortetaksøksen har nr. x 1802. Museumsinspektør N.-A. Boas takkes for tilladelse til at publicere dette stykke.

19) Thomsen og Jessen 1906, s. 22-23, fig. 5. Mathiassen et. al. 1942, s. 25, fig. 9,1.

20) Øksen er et usystematisk fund fremkommet ved gravning af andedamme. Den har nr. A 5218 på Nationalmuseet (OMA). Museumsinspektør P. Asingh, Ebeltoft Museum takkes for tilladelse til at publicere dette stykke.

21) Der er tale om en lille prøveudgravning, der er registreret i FHM j. nr. 1993. Findestedet er Skellerup Enge, Knebel s., Mols h., Randers amt.

22) Schilling 1997, s. 97.

23) S. H. Andersen 1981, s. 20, fig. 8.

24) S. H. Andersen 1981.

25) S. H. Andersen 1970, s. 91-95.

26) Ibid., s. 94. Med hensyn til den såkaldte Monbjergdolk (Vebæk 1939, s. 205 - 206 og fig. 1) er der ingen som helst sikkerhed for, at dette stykke stammer fra Monbjerg (Horsensegnen) eller for den sags skyld fra Jylland. Se også omtalen hos O.Voss 1960, s. 167.

27) Christensen 1993, s. 21.

28) Dette udelukker selvfølgelig ikke, at der kan være tale om et enkeltfund. 
29) Skaarup 1972, s. 86, fig. 30, nr. 1.

30) For en nærmere beskrivelse af stykket fra Sølager henvises til Skaarup 1972, s. 86-87.

31) S. H. Andersen og C. Malmros 1966, s. 69-70 og fig. 21, nr. 15.

32) Albrethsen \& Petersen 1976, s. 8 og fig. 4.

\section{LITTERATUR}

Albrethsen, S. E., V. Alexandersen, E. B. Petersen og J. B. Jørgensen, 1976: De levede og døde .... For 7000 år siden. Fra Nationalmuseets Arbejdsmark 1976.

Albrethsen, S. E. \& E. B. Petersen, 1977: Excavation of a Mesolithic Cemetery at Vedbæk, Denmark. Acta Archaeologica Vol. 47.1976 (1977). København.

Andersen, Søren H., 1970: Flintægdolken fra Flynderhage. Kuml 1969 (1970).

Andersen, Søren H., 1981: Ertebøllekunst. Nye østjyske fund af mønstrede Ertebølleoldsager. Kuml 1980.

Andersen, S. H. og C. Malmros, 1966: Norslund. En kystboplads fra æeldre stenalder. Kuml 1965 (1966).

Andersen, Søren H., og C. Malmros, 1981: Appendix. Dateringen af Norslundbopladsen lag 3 og 4. Kuml 1980 (1981).

Christensen, C., 1993: "Land og hav". I: S. Hvass og B. Storgaard (red.): Da klinger i muld ... 25 ars arkacologi i Danmark. København.

Fischer, A., 1985: Den vestsjællandske Åmose som kultur- og naturhistorisk reservat. Fortidsminder 1985. Antikvariske Studier 7. Fredningsstyrelsen.

Kannegard, E., 1990: Nederst. Arkaologiske udgravninger i Danmark 1991. København.

Larsson, L., 1988: Ett fängstsamhälle för 7000 år sedan. Signum.

Mathiassen et. al., 1942: Dyrholmen. En Stenalderboplads paa Djursland. Det Kongelige Danske Videnskabernes Selskab. Arkcoologisk - Kunsthistoriske Skrifter, Bind I, Nr. 1.

Mertz, E. L., 1924: Oversigt over De sen- og postglaciale Niveauforandringer i Danmark. Danmarks geologiske Undersøgelse, II Rakke. Nr. 41. København.

Petersen, E. B., 1971: En ornamenteret hjortetaksøkse. Fra Nationalmuseets Arbejdsmark 1971.

Petersen, E. B., 1988: Ein mesolithisches Grab mit acht Personen von Strøby Egede, Seeland. Archäologisches Korrespondenzblatt 18, 1988. Heft 2.

Petersen, E. B. \& Petersen, P.V., 1979: Bergmansdal for 7000 år siden. Helsingør Bymuseums Årbog 1978.

Rasmussen, G., H., 1990: Okkergrave fra ældre stenalder på Djursland. Kuml 1988-89 (1990).

Schilling, H.,1997: Bopladsen Korsør Nor. Jæger- og fiskerfolkets permanente tilholdssted i liv og død. I: Pedersen, L., A. Fischer og B. Aaby (red.): Storebelt i 10.000 år. Mennesket, havet og skoven. København.

Skaarup, J., 1972: Hesselø - Sølager. Jagdstationen der südskandinavischen Trichterbecherkultur. Arkæologiske Studier, Vol. 1. København.

Thomsen, Th. og A. Jessen, 1906: Brabrand-Fundet fra den ældre Stenalder, arkæologisk og geologisk behandlet. Aarbøger for nordisk Oldkyndighed og Historie 1906.

Vebæk, C. L., 1939: New Finds of Mesolithic Ornamented Bone and Antler Artefacts. Acta Archaeologica. Vol. IX, 1938 (1939). København.

Voss, O., 1960: Danske flintægdolke. Aarbøger for nordisk Oldkyndighed og Historie 1960. 


\section{A magnificent ornamented axe from the Early Ertebølle Period}

Even in 1)enmark, Mesolithic antler axes with geometric patterns covering the whole surface are a rarity. The ornamented tools from the Early Ertebolle Period in Western Denmark have been published previously (S. H. Andersen 1981), and this article should be considered a supplement to this past work.

The axe shown in fig. 1 was excavated from a sub-marine culture layer at Skærbæk in Eastern Jutland, fig. 7. Consequently, it is a settlement find. The raw material is red deer antler. The axe had been scraped completely smooth and then given a geometric ornamentation covering the whole surface. The main part of the ornamentation had been scratched in a fine and thin line, but a small part had been carried out as a wider and coarser line. The coarser ornamentation is secondary, as it covers the fine line. Ornamentation carried out in two phases has been recorded previously on several other antler axes from Jutland from the Ertebolle Period.

The dominant motif is a regular chessboard pattern, which is repeated in different variations, fig. 1. Analysis of the ornamentation shows - as is the case for several other Danish antler axes - that it was not carried out at the same time but over a considerable period. On the axe from Skærbæk at least 15 different "pattern episodes" can be identified, which partly overlap and therefore must represent a quite long "pattern making period", fig. 2. This theory is supported by the fact that the axe is very polished with use and tremendous grinding.

The net motif is a characteristic ornament of the Early Ertebolle Period, but it is usually carried out in a rhomboid pattern. The regular chessboard ornament on the Skærbæk axe is rare. The other motifs are known from other Jutland antler axes.

According to type, ornamentation and find circumstances, the Skærbæk axe can be dated to the Early Ertebolle Period, c. 540()470() $\mathrm{BC}$. This date matches other finds of ornamented Ertebolle axes in Western Denmark (S.H. Andersen 1981).

Ornamented antler axes are known from several sites in East Jutland, fig. 7, but the surface-covering ornamentation and its regularity makes the Skærbæk axe unusual. This axe belongs to a small "exclusive" group of a few 1)anish, ornamented antler axes from the Late Mesolithic Ertebolle period. They are characterised partly by their surface-covering ornamentation, made in several phases over a long period, using different techniques and compositions, fig.3. A few similar axes are known from Zealand, but none from Northern Germany.

These axes are thought of as ritual objects, but the wear and grinding shows that they were also used in the everyday life.

In spite of the huge difference in space and time, the procedure of successively adding to or covering motifs on the surface of these axes is a clear analogue to the ornamentation of Southwest European caves from the late Ice Age, in which a similar procedure may be observed. The Danish Late Mesolithic antler axes and the cave art presumably reflect a similar ritual backdrop and "function". The vast majority of the West Danish finds of ornamented antler axes are from Eastern Jutland, fig. 7, which probably mirrors a regional character of the cultural conditions of this region during the early Ertebolle Period.

An important parallel to the Skærbæk axe is a recently found, ornamented antler axe from an Ertebolle grave at Fannerup on 1)jursland, fig. 4. Here, too, we are dealing with a completely worn axe with surface ornamentation, the motifs of which are similar to both the Skærbæk axe and the previously published axe from Bogo Nor (S. H. Andersen 1981). The Fannerup axe is important as it shows that ornamented antler 
axes do not just occur as single finds or in settlement sites but are also part of a ritual context connected to the grave cult. Another recently found ornamented antler axe comes from the kitchen midden "Nederst", fig. 5. It is ornamented with finely scratched rhomboids - a motif known from other, earlier finds of ornamented antler axes from the Early Ertebølle culture and which provides a link with the other East Jutland finds with this motif, fig. 7. Finally, an axe from the Ertebølle site "Korsør Nor" (Southwest Zealand) has been published. This axe also has a scratched "sheaf pattern". This is an important find, as it is the first time this pattern occurs in a settlement East of Storebælt, which has hitherto been the border of the distribution area of this motif, fig. 7. The axe from Korsør Nor may be interpreted in two ways: either the sheaf motif had a larger distribution in Denmark during the Early Ertebølle Period than that which has hitherto been assumed, or it represents an example of contact (exchange) between Ertebølle groups west and east of the Storebxlt respectively.

Finally, a revised dating of the flint-edge dagger from Flynderhage is given, fig. 9. This knife has previously been dated to the late Kongemose Culture. However, in the light of the latest published curves of the coast line displacements during the Early Stone Age and several recent finds, for instance from the kitchen midden of "Sølager" and grave 4 from Bøgebakken, fig. 10 and 11, it must be re-dated to the Early Ertebølle Culture.

Soren H. Andersen Marinarkæologisk Forskningscenter Nationalmuseet i Roskilde/

Centre for Maritime Archaeology National Museum of Denmark, Roskilde Translated by Annette Lerche Trolle 